\title{
PRAKTYCZNE POLOŻNICTWO
}




\title{
PRAKTISCHE GEBURTSHILFE \\ UND GEBURTSHILFLICHE OPERATIONEN
}

\author{
von \\ W. PSCHYREMBEL \\ unter Mitarbeit von \\ J. BRETSCHER und D. HOFMANN
}

14. AUFLAGE

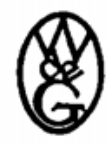

WALTER DE GRUYTER • BERLIN • NEW YORK 


\title{
PRAKTYCZNE POLOŻNICTWO I OPERACJE POŁOŻNICZE
}

\author{
W. PSCHYREMBEL \\ Przy współpracy \\ J. BRETSCHERA i D. HOFMANNA
}

Tłumaczyli

JERZY BRZESKI I HIERONIM KONECKI

WYDANIE I

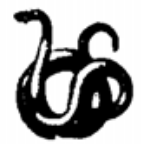

PAŃSTWOWY ZAKŁAD WYDAWNICTW LEKARSKICH WARSZAWA 1974 


\section{WILLIBALD PSCHYREMBEL}

Prof. Dr med., Dr phil., ehem. Chefarzt der Städt. Frauenklinik Berlin-Friedrichshain JURG BRETSCHER

Priv. Doz. Dr med., Chefarzt der Maternité Inselhof Triemli, Zürich DIETRICH HOFMANN

Prof. Dr med., Oberarzt der Universitäts-Frauenklinik Münster, Westfalen

Copyright (C) 1973 by Walter de Gruyter \& Co.

Redaktor naukowy thumaczenia

Prof. dr med. IRENEUSZ ROSZKOWSKI

Projekt oprawy i obwoluty Hanna Mańczak

Redaktor odpowiedzialny Anna Siedlecka

Redaktor techniczny Janina Wiechcinska

Korektor: Magdalena Wesierska

PAŃSTWOWY ZAKLAD WYDAWNICTW LEKARSKICH - WARSZAWA 1974

Wydanie I. Nakład $10000+250$ egz. Objętośc 66,4 ark. wyd. $=55,0$ ark. druk. Papier druk. sat. III kl. 80 g $70 \times 100$. Oddano do skladania w listopadzie 1972 r. Podpisano do druku i druk ukończono w lutym 1974 r. Zam. 1614/72 R-13

DRUKARNIA IM. REWOLUCJI PAŹDZIERNIKOWEJ - WARSZAWA 